and vascular activity of diazoxide. New England Journal of Medicine, 281, 1141.

Steinke, J. \& Soeldner, J.S. (1968) Metabolic effects of diazoxide in normal subjects, patients with diabetes mellitus and with organic hypoglycaemia. Annals of New York Academy of Sciences, 150, 326.

TABACHNiCK, I.I.A. \& Gulbenkian, A. (1968) Mechanisms of diazoxide hyperglycaemia in animals. Annals of New York Academy of Sciences, 150, 204.

UPDike, S.J. \& HARRINGTON, A.R. (1969) Acute diabetic ketoacidosis, a complication of intravenous diazoxide treatment for refractory hypertension. New England Journal of Medicine, 280, 768.

\title{
The treatment of malignant ventricular tachycardia by aorto-coronary saphenous vein bypass graft
}

\author{
H. IKRAM \\ M.B., M.R.C.P., M.R.C.P.E. \\ R. M. JEFFERY \\ M.B., F.R.C.S. \\ R. A. PARKInS \\ M.D., F.R.C.P.
}

\author{
A. R. MAKEY \\ M.S., F.R.C.S. \\ E. R. J. EMERY \\ M.B., F.F.A.R.C.S., D.A. \\ D. L. STONE \\ M.B.B.S., B.Sc.
}

Charing Cross Hospital, London, W.C.2

\section{Summary}

A 61-year-old man with a previous cardiac infarction had at least fifteen attacks of ventricular tachycardia which finally did not respond to either drug or electrical therapy. Angiography showed a blocked right coronary artery and a non-contractile portion of postero-inferior left ventricular wall.

An aorto to right coronary saphenous vein bypass graft was inserted, and although attacks of tachycardia occurred following the operation these were of short duration and reverted spontaneously.

He has been free of tachycardia for 5 weeks, with a greatly improved effort tolerance.

\section{Introduction}

Ventricular tachycardia invariably leads to a severe deterioration of cardiac function in patients with heart disease. The wide range of electrical and pharmacological remedies currently available has greatly improved the outlook in what was formerly a grave complication. Ventricular tachycardia refractory to all available therapy is a rarity nowadays, except as a terminal event in a dying heart.

The purpose of this communication is to describe a case in which a recurring ventricular tachycardia occurred in a patient who had suffered a cardiac infarction some weeks previously. The arrhythmia was refractory to all modes of therapy and caused severe deterioration of haemodynamic function. The tachycardia responded finally to revascularization of the ischaemic myocardium by an aortocoronary saphenous vein bypass graft. As far as we are aware, this is the only case in whom this operation has been performed for intractible life-threatening arrhythmia due to coronary artery disease. The favourable outcome is further evidence for the beneficial effects of this procedure on the function of ischaemic cardiac muscle.

\section{Case report}

Mr J.F. Age 61 years. First presented on the 14 March 1972, with an acute inferior myocardial infarction confirmed electrocardiographically (Fig. 1). On admission to the intensive care unit he suffered a cardiac arrest in ventricular fibrillation. This proved resistant to repeated DC defibrillation. Stable rhythm was finally achieved following administration of $1 \mathrm{mg}$ of propranolol intravenously and subsequent DC shock. The following day he had an attack of ventricular tachycardia at a rate of $150 / \mathrm{min}$, which responded to intravenous lignocaine $(75 \mathrm{mg})$ and sedation with Diazepam and amylobarbitone. 
(a)

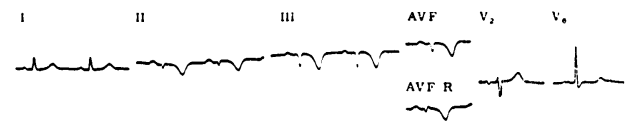

(b)

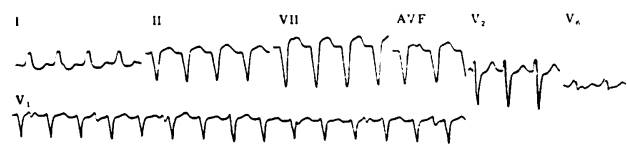

(c)

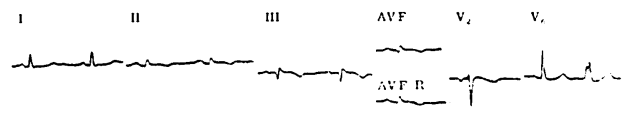

FIG. 1. Electrocardiographs: (a) On first admission with acute posterior infarction; (b) during episode of ventricular tachycardia; (c) following coronary graft.

He remained in sinus rhythm with frequent ventricular ectopics, so procainamide $250 \mathrm{mg}$ q.d.s. was prescribed. This reduced the frequency of the ectopics, but did not abolish them. Oxprenolol $20 \mathrm{mg}$ 6 hourly was substituted, which was later increased to $40 \mathrm{mg} 8$ hourly. On this regime he stayed in sinus rhythm with infrequent ventricular ectopic beats.

He was discharged from hospital after a 5-week stay. No digitalis glycosides were administered and his serum potassium was $4 \cdot 1 \mathrm{mEq} / \mathrm{l}$. There were no signs of thyrotoxicosis $(\mathrm{PBI}=6.3 \mu \mathrm{g} \%)$. At outpatient review on May 19 he was much improved and fully mobile. The ECG showed sinus rhythm with some ventricular ectopics. Three weeks later he was re-admitted complaining of a fluttering sensation in the chest, and dyspnoea on effort; there was no chest pain. Clinical examination and ECG (Fig. 1) confirmed ventricular tachycardia at a rate of $146 / \mathrm{min}$. There were no clinical or radiological signs of congestive cardiac failure. A DC shock resulted in conversion to sinus rhythm.

Oxprenolol $40 \mathrm{mg}$ t.d.s. was continued. The following day multiple ventricular ectopic beats occurred, and oral procainamide $250 \mathrm{mg}$ q.d.s. was given, with little effect. Ventricular tachycardia developed the next day, which did not respond to intravenous lignocaine infusion and sodium phenytoin (250 mg i.v.). Another DC shock (50 joules) resulted in a return to sinus rhythm. Ventricular tachycardia recurred 2 days later despite continued treatment with oral procainamide and oxprenolol.

A transvenous pacing wire was introduced into the right ventricle and electrical 'capture' of the ventricle accomplished with a rate of $120 / \mathrm{min}$ at $6 \mathrm{~V}$ using a Devices pacemaker unit. The rate was reduced to 90/min and 'demand' pacing continued.

Attacks of ventricular tachycardia persisted, despite 'demand' and fixed rate pacing at 100/min.
Eight further episodes of ventricular tachycardia occurred, which were terminated by overdriving the heart with a pacing rate of $135 / \mathrm{min}$ at $10 \mathrm{~V}$. Sustained-action quinidine (Kinidin durules) two t.d.s. was added, and continuous pacing stopped. This appeared to control the ectopic focus, and the pacemaker wire was removed 3 days later.

He remained in sinus rhythm for 6 days when ventricular tachycardia recurred, and underwent spontaneous reversion following the addition of sodium phenytoin $100 \mathrm{mg}$ t.d.s. to the therapeutic regime.

For 14 days he was free of arrhythmia, when further ventricular tachycardia occurred. This episode terminated spontaneously.

Two days later, despite oral therapy with quinidine, phenytoin, oxprenolol and procainamide, he developed ventricular tachycardia, which responded only transiently to DC shock. Transvenous pacing, i.v. practolol, phenytoin, procainamide and i.m. quinidine were all without effect.

The condition of the patient deteriorated progressively. He was dyspnoeic at rest, with a raised venous pressure, blood pressure of $90 / 70 \mathrm{~mm} \mathrm{Hg}$ and bilateral basal rales. Chest X-ray confirmed a progressive increase in cardiac size and pulmonary oedema.

Cine coronary and left ventricular angiography by means of the Judkins transfemoral technique (Judkins, 1967) was carried out under general anaes? thesia. This showed a non-contractile posterodiaphragmatic area in the left ventricle (Fig. 2). The left coronary artery had a minor narrowing in the

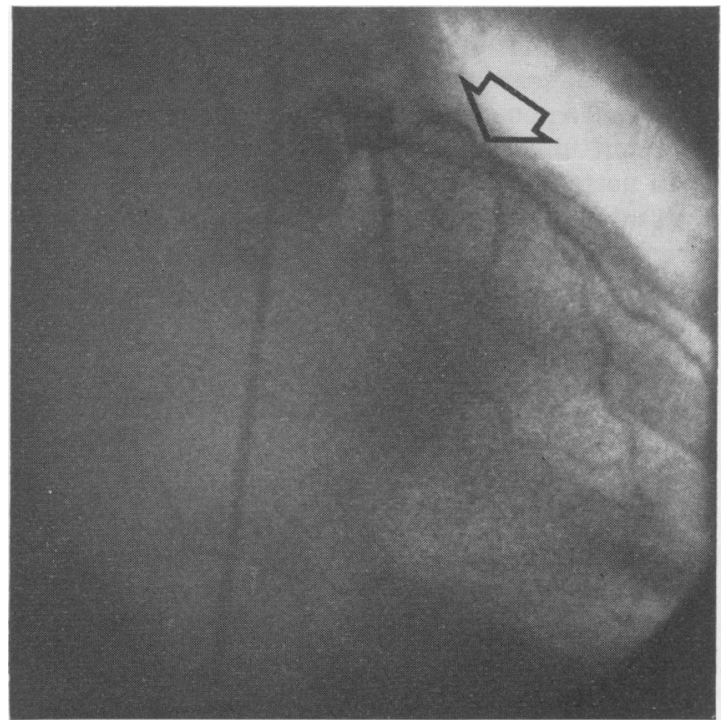

Fig. 2. Left coronary cine angiogram-left posterior oblique position showing minor stenosis of left anterior descending artery (arrowed). 


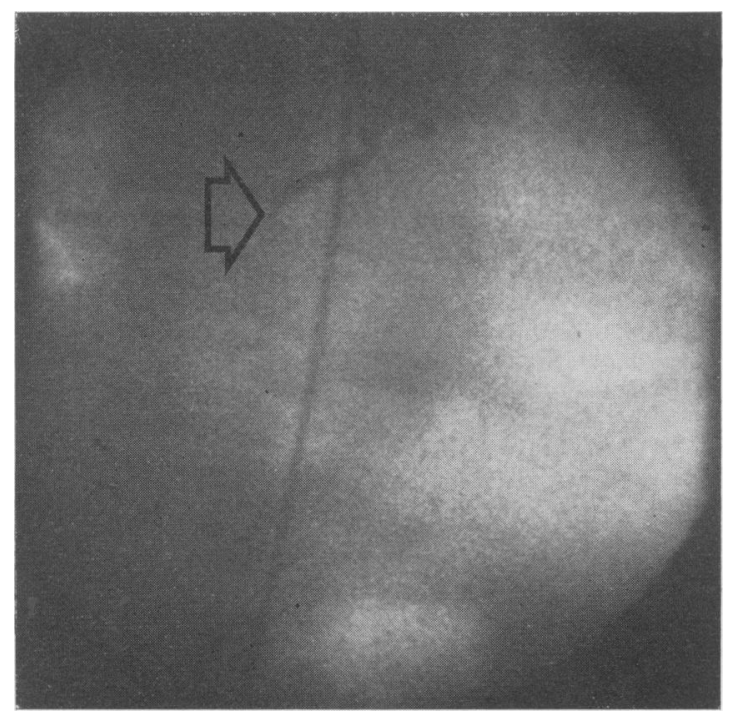

FIG. 3. Right coronary cine angiogram showing the main artery totally obstructed $3 \mathrm{~cm}$ from origin (arrowed).

anterior descending branch, but was otherwise patent (Fig. 3). The right main coronary artery was totally obstructed distal to the right conus branch. No collateral circulation was seen.

The ventricular tachycardia continued for another 2 days, with further deterioration in the clinical state, and so a coronary bypass graft operation was undertaken.

At operation the diagnosis of ventricular tachycardia was confirmed by observation of atrioventricular dissociation with a ventricular rate of $150 / \mathrm{min}$. No definite ventricular aneurysm was present. The right main coronary artery was patent below a complete obstruction approximately $2 \mathrm{~cm}$ from its origin. Some back bleeding occurred on opening the vessel. A saphenous vein graft bypassing the blocked segment of the right coronary artery was inserted. The graft flow was $100 \mathrm{ml} / \mathrm{min}$ measured by S.E. Labs electromagnetic flowmeter. The akinetic area was too extensive and inaccessible to perform the proposed infarctectomy.

At the end of the procedure the patient came off cardiopulmonary bypass still in ventricular tachycardia. Two hours later spontaneous sinus rhythm developed.

Two episodes of ventricular tachycardia occurred in the 2 weeks post-operatively. These were controlled by epicardial pacing for brief periods. He was in normal sinus rhythm for twelve days, on a regular dose of quinidine $(2$ t.d.s.). Following this period he had two brief episodes of ventricular tachycardia, both of which reverted spontaneously to sinus rhythm.
At the time of his discharge from convalescence, he had been in sinus rhythm (Fig. 1) and free from tachycardia for 1 month.

\section{Discussion}

This case report describes a ventricular tachycardia which was resistant to all conventional forms of therapy. As such, it is a highly unusual problem.

When he was re-admitted with ventricular tachycardia, our initial impression was that he had sustained a fresh myocardial infarction to account for the arrhythmia. However, the lack of further change in the ECG, absence of chest pain and the normal levels of SGOT (20 i.u.) and SLDH (213 i.u.) would seem to exclude this possibility. Hyperthyroidism was excluded by absence of clinical findings and a PBI of $6.3 \mu \mathrm{g} \%$.

An alternative explanation was that the scarred area from the initial infarction was acting as an ectopic focus. Although such foci are invariably controllable by anti-arrhythmic therapy, on occasions surgical excision of the scarred area (infarctectomy) has to be carried out before successful control can be achieved (Magidson, 1969).

The excision of scarred tissue is feasible if it is situated in an accessible portion of the heart, and the extent of the area is not too large to seriously reduce the size of the left ventricular cavity. $25-30 \%$ of left ventricular mass is the maximum amount which can be safely resected (Schimert et al., 1969). In this patient, the non-contractile area included virtually the whole of the postero-inferior left ventricular surface. This was too extensive and too inaccessible to excise with safety. Brofman et al. (1956) showed that arrhythmias in coronary artery disease were due to an oxygen gradient between normal and ischaemic muscle, rather than between normal and dead tissue. In accordance with this hypothesis, abolition of the gradient by restoration of blood supply should correct the arrhythmia. This was the rationale for operating on our patient, and the favourable outcome supports Brofman's concept.

It has been shown that ischaemic, though still viable, heart muscle appears akinetic on ventriculography, just as dead muscle does. Furthermore, restoration of its blood flow results in return of contractile function (Chatterjee et al., 1972). Thus excision of akinetic tissue at operation might well remove a substantial portion of potentially functional muscle. We feel that where a discreet aneurysm or obvious scar tissue is present, excision combined with revascularization may be preferable, as it may possibly avoid the persistence of arrhythmia in the early postoperative phase, until the full effects of the revascularization are felt.

Apart from the cure of arrhythmia, this procedure had a beneficial effect on left ventricular function, in 
that the post-operative ventricular tachycardia did not produce hypotension or pulmonary oedema.

The operation of aorto-coronary by-pass has been very successful in the treatment of intractable angina, but objective evaluations of its effect on left ventricular function are few. Chatterjee et al. (1972), Gareth Rees et al. (1971), have shown that this operation does produce symptomatic and measurable improvement in the indices of left ventricular contractility in patients with ischaemic heart disease. The cure of refractory ventricular tachycardia in this case provides further evidence for the beneficial action of aorto-coronary bypass grafting on left ventricular function.

\section{References}

Brofman, K., Leighringer, D., \& Beck, C. (1956) Electrical instability of the heart: Concept of the current of oxygen differential in coronary artery disease. Circulation, 13, 161. 으

Chatterjee, K., Swan, H.S.C., Parmley, W.W., Sustaita, $C$ H., Marcus, H. \& Matloff, J. (1972) Depression of left ventricular function due to acute myocardial ischaemic and? its reversal after aorto-coronary saphenous vein bypass.0 New England Journal of Medicine, 286, 1117.

Gareth Rees, Bristow, J.D., Kremkau, E.L., Green, G.S., $\overline{\bar{c}}$ Herr, R.W., Griswold, H.E. \& Starr, A. (1971) Influence of aorto-coronary bypass surgery on left ventricular per- $\_$ formance. New England Journal of Medicine, 284, 1116.

JUDKINS, M.P. (1967) Selective coronary arteriography. Radiology, 89, 815.

MAGIDSON, O. (1969) Resection of postmyocardial infarction.Ventricular aneurysms for cardiac arrhythmias. Diseases of $\vec{w}$ the Chest, 56, 211.

Schimert, G., Falsetti, W.L., Bunnell, I.L., Dean, D.C. Gage, P.A., Grant, C. \& Greene, D.G. (1969) Excision 3 of akinetic left ventricular wall for intractable heart failure. Annals of Internal Medicine, 70, 437.

\title{
Retroperitoneal rupture of the duodenum due to blunt trauma
}

\author{
J. C. M. Strachan \\ M.B., B.S., F.R.C.S.(Ed.) \\ United Sheffield Hospitals
}

\section{Summary}

The subject is reviewed and a further case of retroperitoneal rupture of the second part of the duodenum due to blunt abdominal trauma in a child is reported. The equivocal initial clinical signs and characteristic $\mathrm{X}$-rays are described.

\section{Incidence}

In a review of the literature from 1902 to 1942 Harrold (1951) found that rupture of the duodenum occurred in $9 \%$ of 717 cases of intestinal rupture due to non-penetrating trauma. Hanley in 1958 quoted the incidence until that time as having been estimated as follows: $10 \%$ of all gastrointestinal ruptures were duodenal, a quarter of those were retroperitoneal, and $90 \%$ of the latter involved the second or third part. In an analysis of eighty-six traumatic duodenal injuries Burrus, Howell and Jordan (1961) found that only $10 \%$ of these injuries were due to blunt trauma, and Webb et al. (1958) found similarly that in their series of fifty duodenal injuries $10 \%$ followed blunt trauma. Under these conditions the duodenal lesion tended, in a higher percentage of cases, to be much more severe than that due to a penetrating? wound. It would also appear reasonable to expecto the incidence of retroperitoneal perforation to be . $^{-}$. higher after blunt trauma and that of intra-peritoneal perforation to be higher after penetrating wounds. This is partly confirmed by the findings of McCorto (1966) who gives the order of frequency of duodenal injuries following blunt abdominal trauma as:

(1) intramural haematoma;

(2) retroperitoneal perforation;

(3) intraperitoneal perforation.

This has, therefore, been a relatively rare lesion but has probably started to increase in frequency overo the past two decades with the increasing numbers of motor vehicle crashes. Roman, Silva, and Lucas (1971) reported that at fifty laparotomies performede for blunt abdominal trauma each year over a 10 yearo period, approximately $5 \%$ of the patients had $a^{+}$ duodenal injury. Eighteen of the twenty-three? patients with duodenal injuries in their series (from Detroit) had been involved in automobile accidents, $\frac{?}{\mathbb{Q}}$ 